\title{
Genetic mechanisms in the repression of flowering by gibberellins in apple (Malus $\mathrm{x}$ domestica Borkh.)
}

\author{
Songwen Zhang, Christopher Gottschalk and Steve van Nocker ${ }^{*}$ (D)
}

\begin{abstract}
Background: Gibberellins (GAs) can have profound effects on growth and development in higher plants. In contrast to their flowering-promotive role in many well-studied plants, GAs can repress flowering in woody perennial plants such as apple (Malus $x$ domestica Borkh.). Although this effect of GA on flowering is intriguing and has commercial importance, the genetic mechanisms linking GA perception with flowering have not been well described.

Results: Application of a mixture of bioactive GAs repressed flower formation without significant effect on node number or shoot elongation. Using Illumina-based transcriptional sequence data and a newly available, high-quality apple genome sequence, we generated transcript models for genes expressed in the shoot apex, and estimated their transcriptional response to GA. GA treatment resulted in downregulation of a diversity of genes participating in GA biosynthesis, and strong upregulation of the GA catabolic GA2 OXIDASE genes, consistent with GA feedback and feedforward regulation, respectively. We also observed strong downregulation of numerous genes encoding potential GA transporters and receptors. Additional GA-responsive genes included potential components of cytokinin (CK), abscisic acid (ABA), brassinosteroid, and auxin signaling pathways. Finally, we observed rapid and strong upregulation of both of two copies of a gene previously observed to inhibit flowering in apple, MdTFL1 (TERMINAL FLOWER 1).

Conclusion: The rapid and robust upregulation of genes associated with GA catabolism in response to exogenous GA, combined with the decreased expression of GA biosynthetic genes, highlights GA feedforward and feedback regulation in the apple shoot apex. The finding that genes with potential roles in GA metabolism, transport and signaling are responsive to GA suggests GA homeostasis may be mediated at multiple levels in these tissues. The observation that TFL 1-like genes are induced quickly in response to GA suggests they may be directly targeted by GA-responsive transcription factors, and offers a potential explanation for the flowering-inhibitory effects of GA in apple. These results provide a context for investigating factors that may transduce the GA signal in apple, and contribute to a preliminary genetic framework for the repression of flowering by GAs in a woody perennial plant.
\end{abstract}

Keywords: Gibberellin (GA), Apple, Flowering, GA2 OXIDASE (GA2OX), TERMINAL FLOWER 1 (TFL1), FLOWERING LOCUS T(FT)

\footnotetext{
* Correspondence: vannocke@msu.edu

Department of Horticulture and Graduate Program in Plant Breeding,

Genetics, and Biotechnology, Michigan State University, 390 Plant and Soil

Science Building, 1066 Bogue St., East Lansing, MI 48824, USA
}

(c) The Author(s). 2019 Open Access This article is distributed under the terms of the Creative Commons Attribution 4.0 International License (http://creativecommons.org/licenses/by/4.0/), which permits unrestricted use, distribution, and reproduction in any medium, provided you give appropriate credit to the original author(s) and the source, provide a link to the Creative Commons license, and indicate if changes were made. The Creative Commons Public Domain Dedication waiver (http://creativecommons.org/publicdomain/zero/1.0/) applies to the data made available in this article, unless otherwise stated. 


\section{Background}

Gibberellins (GAs) are a class of phytohormones that have profound effects on many aspects of plant growth and development. GAs are required for such diverse functions as mobilization of starch reserves in barley aleurone cells, seed germination in response to stratification or light signals, and promotion of hypocotyl and stem elongation in darkness or shade [1]. GAs also have a well-documented role to promote flowering in longday rosette plants such as the research reference Arabidopsis thaliana (Arabidopsis) [1]. At the cellular level, GAs have been best characterized as promoting cell elongation, but whether this mechanism drives all of its organismal functions remains unclear [2].

GAs comprise a wide variety of diterpenoid compounds sharing a 19- or 20-carbon tetracyclic structure. To date, 136 molecularly distinct GAs have been identified, designated as $\mathrm{GA}_{1}-\mathrm{GA}_{136}$. However, only $\mathrm{GA}_{1}$, $\mathrm{GA}_{3}, \mathrm{GA}_{4}$ and $\mathrm{GA}_{7}$ are known to have biological activity in higher plants [3]. The initial GA in the biosynthetic pathway, $\mathrm{GA}_{12}$, is synthesized from GGPP (trans-geranylgeranyl diphosphate) in the chloroplast, via a series of enzymes including CPS (ent-copalyl diphosphate synthase), KS (ent-kaurene synthase), KO (ent-kaurene oxidase), and KAO (ent-kaurenoic acid oxidase). GA20ox (GA20-oxidase) is responsible for the removal of C20 (carbon 20) to form C19-GAs $\left(\mathrm{GA}_{9}\right.$ and $\left.\mathrm{GA}_{20}\right)$, and further oxidation by GA3ox (GA3-oxidase) results in the final formation of the bioactive GAs [3]. The GA2ox (GA2 oxidase) group of enzymes catalyze the oxidation of both bioactive (except $\mathrm{GA}_{3}$ ) and inactive GAs, and thus represent an important mechanism for catabolism of GAs and the resetting of GA signaling [4]. Additional mechanisms for inactivation of bioactive GAs include oxidation by the EUI/ELA class of cytochrome p450 monooxygenases, which target non-13-hydroxylated GAs such as $\mathrm{GA}_{4}$ [5-7].

GAs can be transported across the plasma membrane by several members of the Nitrate transport 1/Peptide transporter family (NPF), which also participate in transporting a wide range of other substrates [8]. At least NPF2.10, NPF3.1 and NPF4.1 have been shown to transport bioactive GAs $\left(\mathrm{GA}_{1}, \mathrm{GA}_{3}\right.$, and $\left.\mathrm{GA}_{4}\right)$ [9-12]. In Arabidopsis, NPF3.1 can also transport biologically inactive GAs $\left(G_{9}, G A_{12}\right.$, and $\mathrm{GA}_{20}$ ) and the GA catabolite, $\mathrm{GA}_{8}$ [12].

At the molecular level, the GA signaling pathway comprises three elements: (1) GID1 (GIBBERELLIN-INSENSITIVE DWARF 1) proteins, which act as GA receptors, (2) a class of transcriptional effector proteins designated DELLA, and (3) a set of transcription factors that initiate changes in downstream GA response-associated genes [13]. In all contexts studied so far, binding of GA to GID1-type receptors promotes interaction between GID1 and a DELLA protein, which then triggers targeting of the
DELLA protein by the SCF ${ }^{\text {GID2/SLY1 }}$ complex $[13,14]$. $\mathrm{SCF}^{\mathrm{GID} 2 / \mathrm{SLY} 1}$ is an E3 ligase that directs ubiquitination of the targeted DELLA proteins, hence initiating their degradation by the $26 \mathrm{~S}$ proteasome [14]. DELLA proteins can influence transcription by directly interfering with the function of transcription factors, or by activating transcription directly [15].

Plants have several mechanisms to maintain GA at a certain level (GA homeostasis). In plant tissues, GA homeostasis can be maintained through both repression of GA biosynthesis and promotion of GA catabolism. Repression of biosynthesis (feedback regulation) is known to be mediated by decreased expression of the GA biosynthetic genes, GA20OX and GA3OX, whereas promotion of catabolism (feedforward regulation) results from increased expression of the GA catabolic genes, GA2OX [16-19]. GA homeostasis has also been shown to be achieved via feedforward regulation of DELLA genes, and feedback regulation of receptor and transporter genes [12, 20, 21].

In Arabidopsis, GAs promote floral induction by upregulating the floral meristem identity genes $S O C 1$ (SUPPRESSOR OF OVEREXPRESSION OF CO 1) and $L E A F Y$ ( $L F Y)$ [22-24]. The regulation of $L F Y$ is at least in part dependent on binding of the GA-MYB transcription factor, AtMYB33, to a regulatory element within the $L F Y$ promoter [25]. GA can also promote floral induction by regulating SPL (SQUAMOSA PROMOTER BINDING-LIKE) genes, which encode transcription factors that positively regulate the expression of $S O C 1$ and $L F Y$ [26]. In addition, GA promotes the expression of the FT (FLOWERING LOCUS T) gene in Arabidopsis leaves [27]. FT encodes the protein that is believed to be the florigen and transported from leaf to shoot apical meristem [28, 29]. Ultimately, increased expression of $S P L, S O C 1, L F Y$ and $F T$ promote expression of $A P E-$ TALA1 (AP1) and other genes that direct flower formation [30].

The promotion of flowering by GAs in Arabidopsis is in contrast to the generally repressive effects of GAs on flowering in some woody perennial plants including apple [31, 32], peach [33], citrus [34], and grapevine [35]. Domesticated apple trees have a biennial (two-year) flowering cycle, such that flowers are initiated during the growing season in the first year and complete development and bloom in the growing season of the second year. Application of either $\mathrm{GA}_{3}$ or a mixture of $\mathrm{GA}_{4}$ and $\mathrm{GA}_{7}\left(\mathrm{GA}_{4+7}\right)$ to whole trees during the period of floral induction in the first year can reduce bloom the second year [32, 36-40]. When carried out in commercial operations, the reduction in fruit load enhances fruit size and quality [41-43].

Although the repressive effect of GAs on flowering in apple has great commercial importance, there is little understanding of the fundamental mechanisms. This 
lack of knowledge has limited the development of more efficient methods to control flowering in apple, and the breeding of new cultivars with more desirable flowering traits [44-46]. It has been hypothesized that the effect of GAs in apple may be mediated through inhibiting activity of cytokinins (CK), which have been shown to promote floral initiation $[47,48]$, but the molecular relationship between GA and CK in apple has not been well studied. Underlying this deficit in knowledge is the lack of fundamental information about GA-responsive gene expression in apple and other woody perennial plants. Ultimately, the repression of flowering by GA is expected to be driven by changes in the expression of those apple genes that have key roles in flowering. Haberman et al. [49] found that GA applied to apple early in the growing season $(\sim 30$ DAFB) led to increased expression of the MdTFL1-2 gene, one of two TFL1 homologs in apple, late in the season when flowers would be forming. Previous studies found that apple TFL1 gene(s) repressed flowering when expressed ectopically in Arabidopsis [50], while antisense expression of these genes in apple led to abbreviation of the juvenile phase and early flowering [51]. However, it was unclear whether the increased expression of MdTFL12 late in the season observed by Haberman et al. [49] reflected a direct action of GA on the MdTFL1-2 gene, or rather if MdTFL1-2 expression was an indirect result of floral repression. This is conceivable, because in Arabidopsis, TFL1 is negatively regulated by $L F Y$ and $A P 1$ [52].

In this study, we documented the transcriptional network influenced by exogenous GA in the apple shoot apex under conditions that repress floral induction, as a first step to understand the flowering-repressive role of GA in woody perennial plants.

\section{Results}

\section{Repression of flower formation by GA}

Like many commercial apple cultivars, 'Gala' produces flowers in an inflorescence that forms terminally on short shoots called spurs. Growth in the subsequent season originates from a dominant apical bud subtending the inflorescence. These new shoots, called bourse shoots, typically produce four to six leaves in a rosette and terminate with inflorescence primordia, reiterating the previous season's structure. Alternatively, bourse shoots may remain vegetative, and occasionally these elongate to form lateral branches. To demonstrate the influence of GA on flowering and generate material for molecular analyses, we applied a commercial formulation of a $\mathrm{GA}_{4} / \mathrm{GA}_{7}$ mixture as a foliar spray to 'Fulford Gala' trees, approximately 35 days after full bloom (DAFB). This treatment was timed to coincide with early floral induction, based on published data for this cultivar $[53,54]$ and our preliminary observations (not shown). All flowers were removed from these trees just before bloom, to avoid potential influences of bioactive GAs generated by developing fruit [55]. To minimize unanticipated effects on growth and development, we used a relatively low $(200 \mathrm{ppm})$ concentration of GAs. Consistent with previous observations on the effect of GAs in apple, this treatment led to subtle, but significant, repression of flowering (Fig. 1a), without significantly altering shoot architecture, as evaluated by quantifying shoot length and node number (Fig. 1b).

\section{Gene expression within the bourse shoot apex}

To assess the effect of exogenous GAs on the transcriptional landscape within the bourse shoot apex in the context of flowering, we carried out sequencing-based transcriptional profiling (RNA-seq) of the bourse shoot apex, which contains the apical meristem, subtending leaf primordia, and underlying tissues, including pith and vasculature. Collections were made at 1,2, 5, and 15 days after GA treatment (DAT). RNAs were subjected to sequencing using the Illumina HiSeq platform and 101-base, paired-end reads. The resulting $\sim 379$ million read pairs (Additional file 1: Table S1) were aligned to a recently released, Malus x domestica genome sequence (GDDH13) [56] and assembled into transcript models (Additional file 2).

The exhaustive depth of our transcriptional data and recent availability of a high-quality apple genome sequence provided the opportunity to document genes expressed in the apple bourse shoot apex with high resolution and accuracy. When analyzed collectively, this data supported the expression of 84,732 distinct transcripts (Additional file 3) from 40,487 loci (Additional file 4). About $81 \%$ of these loci $(32,794)$ had been previously annotated as protein-coding or noncoding genes in the apple reference genome [56] (Additional file 4). Among the remaining 7693 loci, 6952 would generate transcripts showing no overlap with exons of annotated reference genes (Additional file 5: Table S2). As anticipated, most of these showed strong homology to genes that had previously been identified from apple, but that were absent from the reference genome annotation (Additional file 5: Table S3). Transcripts from 970 additional loci had not previously been identified in apple, although they showed significant homology with sequences that had been described previously in other plant species (Additional file 5: Table S3). A further 1291 loci lacked significant homology to any sequence in current public databases, including the draft Malus x domestica genome sequence (Additional file 5: Table S4). Compared with the apex transcriptome as a whole, these novel unknown loci were weakly expressed (median FPKM $<1$ ), and generated relatively short transcripts (median length $382 \mathrm{bp}$ ) (Additional file 5: Table S4). Because these transcripts were modeled on sequence reads that were aligned with the reference genome, they likely represent authentic apple 

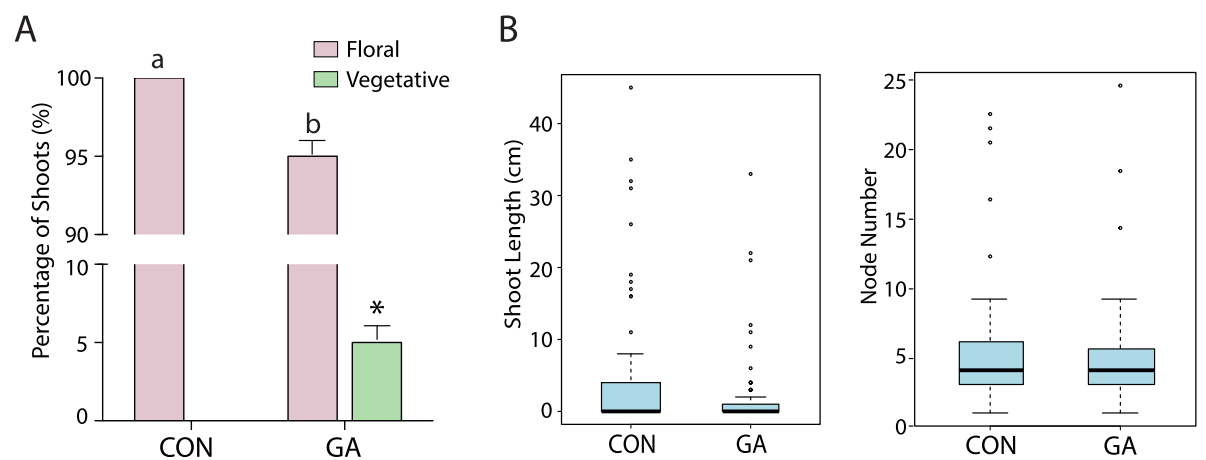

Fig. $1 \mathrm{GA}_{4+7}$ treatment led to significant repression of flowering without altering shoot architecture. a Percentage of floral and vegetative shoots initiating from spurs on control (CON) and GA-treated trees. Shoots were evaluated during early spring the year following the experiment. Letters and the asterisk above the bars indicate statistically significant differences between GA-treated trees and control (analysis of variance, $p<0.05$ ). $\mathbf{b}$ Length and node number of bourse shoots initiated from spurs on control and GA-treated trees. Shoots were evaluated at the end of the growing season. Boxes represent the median, 25th and 75th percentile values; error bars show outlier boundaries (inter-quartile range); bubbles above represent outliers

loci, rather than contamination of the sequence dataset by exogenous biota. The reference genome contained 16,694 loci that were not supported by our data from the apple bourse shoot apex (Additional file 5: Table S2), consistent with the broad mRNA sequence representation used in annotation of the GDDH13 reference genome [56], and the highly restricted tissue source used in this study. A revised feature coordinate map of the GDDH13 reference genome including both the previously and newly annotated loci is presented as Additional file 6.

\section{Transcriptional response of GA signaling components}

By comparing sequence representation for transcript models in shoot apices from GA-treated vs. control trees, we identified genes and transcripts whose abundance was influenced by GAs. We found 1476 genes that showed a significant transcriptional response to GA treatment at one or more of the four time points (Fig. 2 and Additional file 7: Table S5). Analysis of this subset of gene for potential ontology revealed overrepresentation for several bioprocess terms, including two related to GA: 'gibberellin biosynthetic process' and 'response to gibberellin'. An independent analysis of potential molecular interactions (KEGG pathway) revealed overrepresentation for two pathway terms associated with GA metabolism and signaling: 'diterpenoid biosynthesis' and 'plant hormone signal transduction' (Additional file 8: Tables S6 and S7). These findings are consistent with the expected disruption of GA signaling in response to exogenous bioactive GA.

Of the apple GA-regulated genes that could be classified by GO (Gene Ontology) bioprocess and KEGG pathway enrichment analyses, 29 were included in at least one of these GA-associated groups (not shown). These genes collectively represented the breadth of known genes associated with GA metabolism and signaling. Two genes closely related to KS1 and GA20OX, and thus potentially participating in biosynthesis, were significantly downregulated at

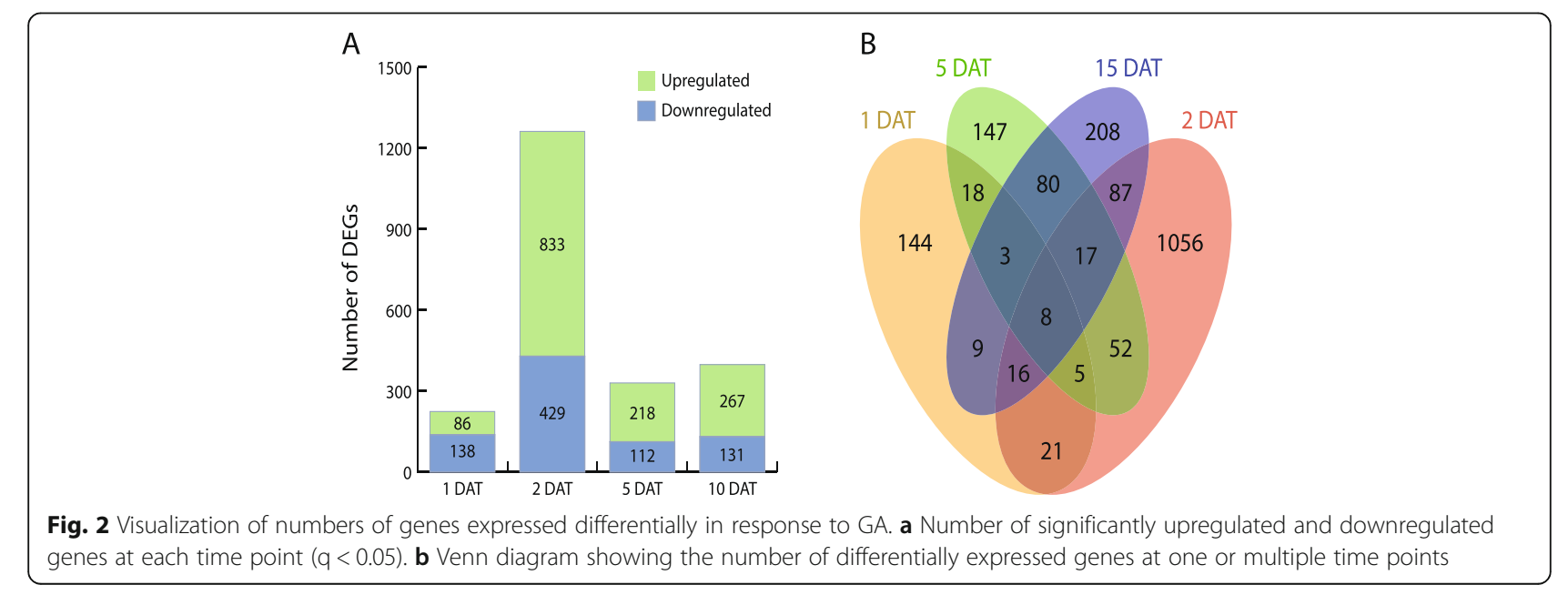


2 DAT and 15 DAT, respectively (Table 1). In contrast, four distinct GA2OX homologs showed increased expression at least at three of the time points (Table 1 and Fig. 3). This opposing influence of GA on GA20OX and GA2OX gene expression in apple is consistent with that previously observed by Haberman et al. [49], and is suggestive of GA feedback and feedforward regulation. To document this in more detail, we identified all potential GA biosynthetic (KAO, KO, CPS, GA20OX, GA3OX) and catabolic (GA2OX) genes in our dataset, based on sequence homology with functionally characterized genes from Arabidopsis (Additional file 9: Table S8), and estimated their expression at all four time points following GA application, relative to non-treated samples (Fig. 4). This showed that $\mathrm{GA}_{4+7}$ generally repressed the expression of GA biosynthetic genes. In contrast, $\mathrm{GA}_{4+7}$ generally promoted expression of an assortment of GA2OX genes. This was most apparent for those GA2OX genes representing Class I and Class II enzymes, which target C19-GAs and thus are capable of inactivating bioactive GAs (Fig. 4). Inspection of the GA-responsive genes that were not annotated with GA-related ontology terms identified a homolog of EUI/ELA1, which encodes a $\mathrm{GA}_{4}$ catabolic enzyme and represents another GA deactivation pathway [5-7]. This EUI/ELA1-like gene was moderately upregulated at 15 DAT (Additional file 7: Table S5).
In addition, GA strongly downregulated the expression of 2 GA transporter-like genes, related to NPF3.1 (NITRATE TRANSPORTER AND PEPTIDE TRANSPORTER FAMILY 3.1) (Fig. 5a) and 3 GA receptor-like genes, related to GID1 (Fig. 5b). Interestingly, all five of these genes showed a similar temporal response to GA: little or no response at 1 DAT, strongest downregulation at 2 DAT, subtle downregulation at $5 \mathrm{DAT}$, and moderate downregulation at 15 DAT. This finding suggests a common but complex mechanism for regulation of these genes. GA also downregulated two genes homologous to Arabidopsis $S L Y 1$ (or rice GID2), whose product is a component of the E3 ligase that targets DELLA proteins for degradation (Table 1). In contrast, two genes encoding potential DELLA proteins, GAI (GIBBERELLIC ACID INSENSITIVE) and RGL2 (REPRESSOR OF GA-LIKE 2), were upregulated by GA at 2 DAT (Table 1). In summary, the expression of genes participating not only in GA metabolism, but also various signaling steps, were responsive to GA.

In addition to the GA pathway, exogenous GA also altered expression of genes with potential functions in other hormonal signal transduction pathways (Additional file 8: Table S7; Additional file 10: Table S9), including the CK, auxin, abscisic acid (ABA) and brassinosteroid pathways. Specifically, GA persistently downregulated the expression of two genes encoding homologs of AHP1, a histidine phosphotransfer protein connecting CK receptors with

Table 1 GA-associated differentially expressed genes

\begin{tabular}{|c|c|c|c|c|c|c|c|}
\hline \multirow[t]{2}{*}{ Terms } & \multirow[t]{2}{*}{ Gene ID } & \multirow{2}{*}{$\begin{array}{l}\text { Arabidopsis } \\
\text { Homolog ID }\end{array}$} & \multirow[t]{2}{*}{ Gene } & \multicolumn{4}{|c|}{ Log2(Fold Change) $^{a}$} \\
\hline & & & & 1 DAT & $2 \mathrm{DAT}$ & 5 DAT & 15 DAT \\
\hline \multicolumn{8}{|c|}{ Gibberellin biosynthetic process } \\
\hline & $\begin{array}{l}\text { MD10G1215700, } \\
\text { MD10G1215900, } \\
\text { MD10G1216200 }\end{array}$ & AT1G79460.1 & GA2, KS, ATKS1 & & -1.13 & & \\
\hline & MD00G1003600 & AT5G51810.1 & GA200X2, AT2353 & & & & -1.12 \\
\hline & MD05G1283800 & AT1G30040.1 & ATGA2OX2, GA2OX2 & & 2.04 & 0.98 & 1.58 \\
\hline & MD10G1262000 & AT1G30040.1 & ATGA2OX2, GA2OX2 & 1.93 & 2.09 & 1.15 & 2.11 \\
\hline & MD10G1194100 & AT1G78440.1 & ATGA2OX1, GA2OX1 & 1.56 & 0.92 & 0.81 & 1.54 \\
\hline & MD05G1207000 & AT1G78440.1 & ATGA2OX1, GA2OX1 & & 1.99 & 2.1 & 2.48 \\
\hline & MD14G1234300 & AT1G02400.1 & ATGA2OX4, ATGA2OX6, DTA1 & & & & -2.86 \\
\hline \multicolumn{8}{|c|}{ Response to gibberellin } \\
\hline & MD15G1180500 & AT1G14920.1 & GAl, RGA2 & & 1.09 & & \\
\hline & MD03G1273300 & AT3G63010.1 & ATGID1B, GID1B & -1.45 & -3.62 & & -1.41 \\
\hline & MD11G1296000 & AT3G63010.1 & ATGID1B, GID1B & -1.02 & -2.22 & & -0.84 \\
\hline & MD04G1212400 & AT5G27320.1 & ATGID1C, GID1C & & -1.23 & & -0.79 \\
\hline & MD17G1260700 & AT3G03450.1 & RGL2 & & 0.88 & & \\
\hline \multicolumn{8}{|c|}{ Plant hormone signal transduction } \\
\hline & MD08G1091700 & AT4G24210.1 & SLY1 & & -1.74 & & -1.51 \\
\hline & MD15G1075800 & AT4G24210.1 & SLY1 & & -1.2 & & -0.89 \\
\hline
\end{tabular}

${ }^{a} \log _{2}$ (Fold Change) is the $\log _{2}$ value of expression level in GA-treated buds versus that in control. Only significantly different values are listed in table 
MD05G1207000 (GA2OX1)

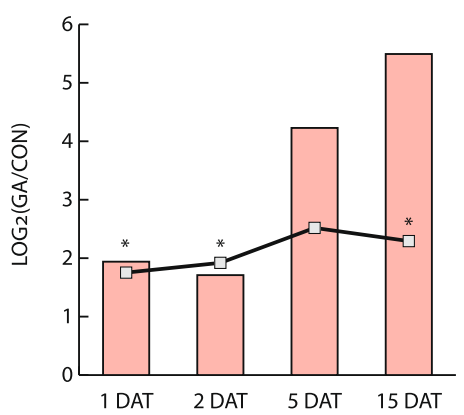

MD05G1283800 (GA2OX2)

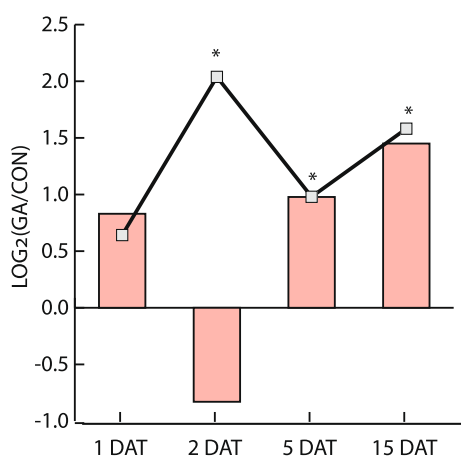

qPCR $\rightarrow-R N A s e q$

MD10G1194100 (GA2OX1)

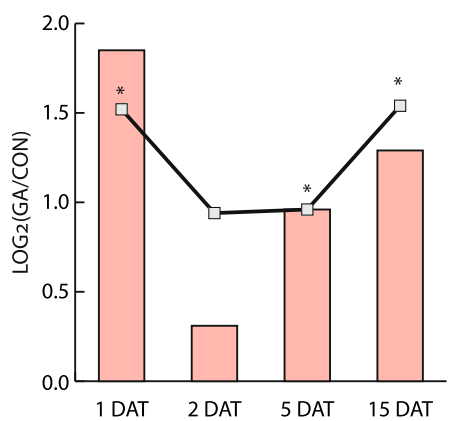

MD10G126200 (GA2OX2)

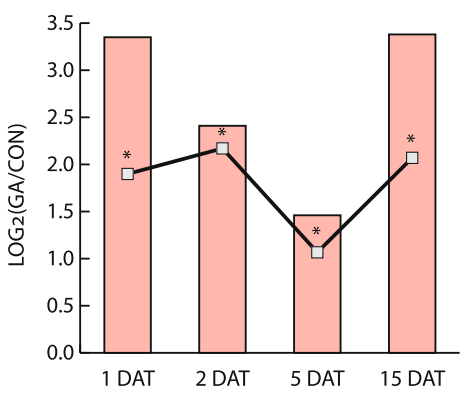

Fig. 3 Four GA2OX genes were expressed to significantly higher levels in GA-treated shoot apices. Lines and significance (asterisk $*, p<0.01)$ were based on RNA-seq data, while bars were based on RT-PCR data. $\log _{2}(G A / C O N)$ denotes $\log _{2}$ (Fold Change)

CK-mediated transcription (Additional file 10: Table S9). Consistent with its antagonism with ABA signaling in various developmental events, GA repressed the expression of potential key components in ABA signaling, which includes its receptors, as well as positive and negative signal mediators (Additional file 10: Table S9). GA was also associated with diminished expression of three genes with potential roles in brassinosteroid biosynthesis (Additional file 10: Table S9). In contrast to its repressive role in regulation of CK-, ABA - and brassinosteroid-related genes, GA widely upregulated the expression of potential components of auxin signaling, including an auxin receptor and negative and positive regulators (Additional file 10: Table S9). Taken together, these results suggest that, in the shoot apex at this developmental stage, GA signaling interacts extensively with other hormonal signaling pathways.

\section{Transcriptional response of potential flowering genes}

An unresolved question is the identity of flowering genes that may mediate the repressive effect of GA on flowering in apple. The timing of our analysis - between 35 and 50 DAFB, precedes the seasonal time at which floral differentiation is typically observed in this cultivar under these conditions (not shown). Consistent with this, GO terms related to flower formation were not enriched within the set of GA-responsive genes. An inspection of the set of GA-responsive genes identified four with annotations related to floral initiation. Two of these were closely related to $A P 1$, and based on nucleotide sequence may represent the counterpart(s) of MdMADS2 and/or $M d M A D S 5$, which had previously been shown to promote flowering when expressed heterologously in transgenic Arabidopsis or tobacco [57, 58]. Consistent with a presumed role promoting flowering, both of these AP1-like genes were expressed to significantly lower levels in GAtreated trees relative to controls, but this difference was seen only at a single time point (2 DAT) (Additional file 7: Table S5).

The remaining GA-responsive, annotated flowering genes were $M d T F L 1-1$ and MdTFL1-2. Both genes were expressed to substantially higher levels in GA-treated trees compared with non-treated trees at 1,2 and 15 DAT (Fig. 6a). MdTFL1-2 was previously reported to be expressed to higher levels in the shoot apex of GAtreated vs. non-treated trees, but only very late in the 


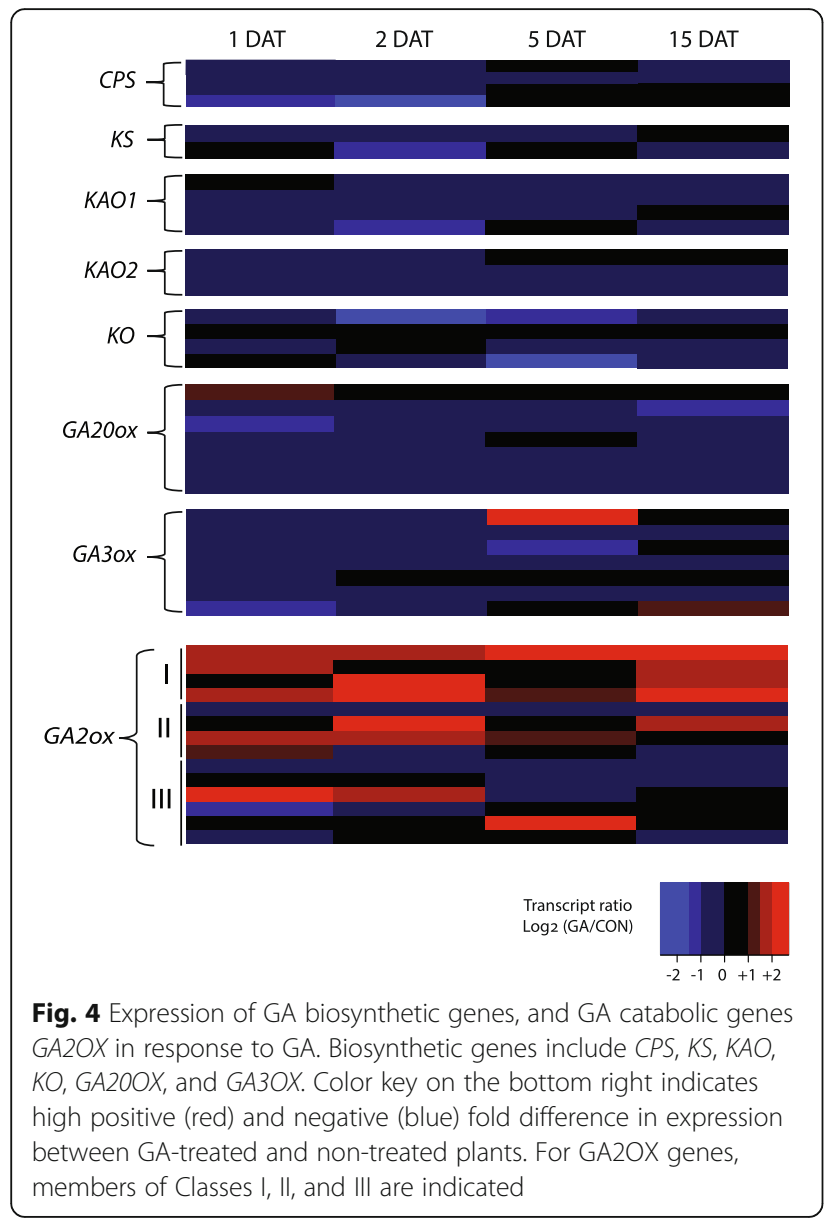

growing season when flowers would be forming [49]. To further investigate a potential rapid influence of $\mathrm{GA}_{4+7}$ on MdTFL1-1/MdTFL1-2 gene expression, we carried out a supplementary and independent transcriptional analysis. Five-year-old 'Brookfield Gala' trees, a clone of 'Gala' characterized by strongly striped fruit, were treated with a single application of $200 \mathrm{ppm} \mathrm{GA}_{4+7}$ at $30 \mathrm{DAFB}$, and gene expression was evaluated in the shoot apices of treated and non-treated control trees at 5, 10, 28 and 50 days following treatment, corresponding to 35 to 80 DAFB. In non-treated trees, both MdTFL1-1 and MdTFL1-2 showed a slight increase in expression between 35 and 40 DAFB, and steadily decreasing expression thereafter (Fig. 6b). Neither MdTFL1-1 nor MdTFL1-2 appeared to be expressed strongly at 80 DAFB. However, both MdTFL1-1 and MdTFL1-2 were expressed to significantly higher levels in GA-treated trees at 10 DAT (Fig. 6b), consistent with the immediate, GA-associated promotion of expression seen in the initial experiment.

We analyzed our datasets for expression of apple counterparts of four components linking GA with flowering in Arabidopsis - GAMYB33, SOC1, FT, and $L F Y$. Although the GDDH13 apple reference genome includes clear homologs of these genes, and corresponding transcriptional models suggest that several were expressed in the apex, our data did not support their regulation by GA within the 15-d time frame at this developmental stage (Additional file 9: Table S8 and not shown). We examined FT more closely, because both of the two copies of FT in apple (MdFT1, MdFT2) have been shown previously to promote flowering when expressed ectopically in transgenic apple [59]. Consistent
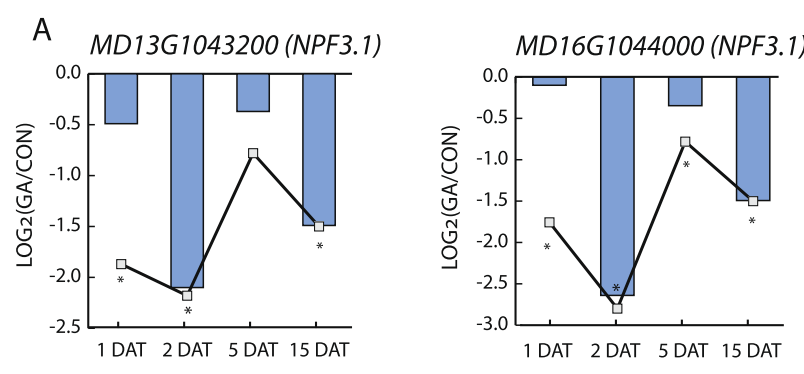

$\square$ qPCR $\quad \square$ RNAseq
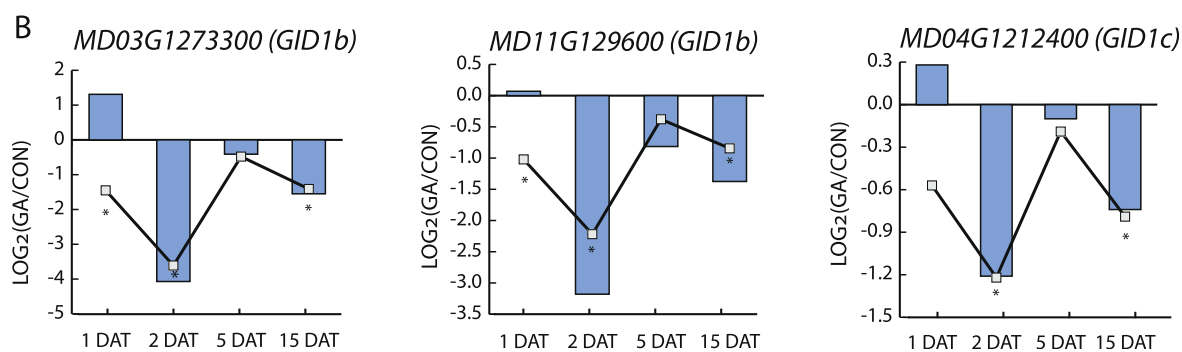

Fig. 5 Downregulation of GA transporter- and receptor-like genes. a GA transporter-like genes, NPF3.1; $\mathbf{b}$ GA receptor like genes, GID1. Lines and significance (asterisk *, $p<0.01$ ) were based on RNA-seq data, while bars were based on RT-PCR data. $\log _{2}(G A / C O N)$ denotes Log 2 (Fold Change) 
A
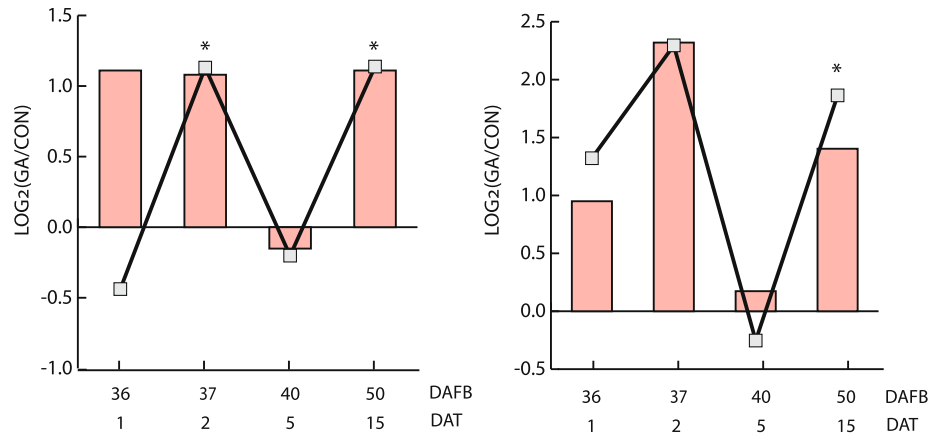

B MD12G1023900 (TFL1-1)

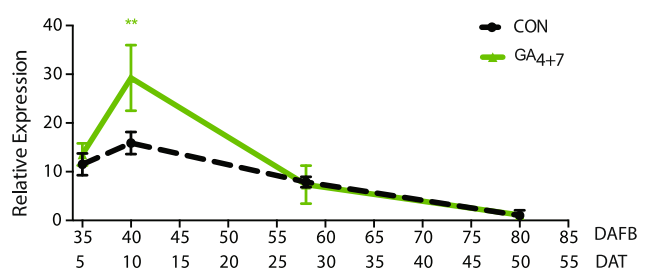

MD14G1021100 (TFL1-2)

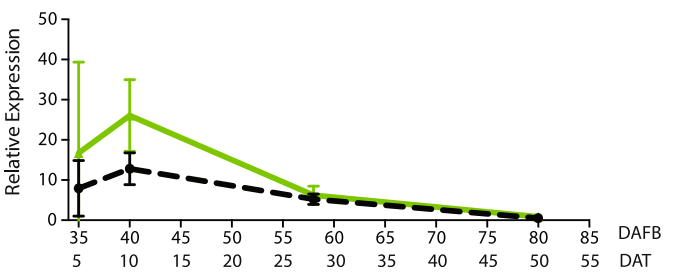

Fig. 6 Upregulation of two apple TFL1-like genes in response to GA. a RNA-seq (line) and gPCR (column) measurement for 'Fulford Gala'. Asterisk $\left(^{*}\right)$ denotes the difference between the expression of the gene in GA-treated sample and that in control was significant $(p<0.01)$. Log $2(G A / C O N)$ denotes Log $_{2}$ (Fold Change). b QPCR measurement for 'Brookfield Gala'. Green line represents relative expression in GA $4+7$-treated bourse shoot apex, and black dashed line represents CON. Double asterisks (**) denote significant difference between CON and GA ( $p<0.01)$. Error bars represent standard deviations. Double time scales are given on $\mathrm{Y}$ axis: DAFB, days after full bloom; DAT, days after treatment

with previous observations [59], our analysis of RNA-seq read counts (Additional file 11: Figure S1a), and qPCR analysis (Additional file 11: Figure S1b), suggested that, in the shoot apex of non-treated trees, MdFT1 was expressed moderately, whereas MdFT2 was expressed at only very low levels. Similar to the results of the initial transcriptional profiling analysis, expression of $M d F T 1$ was unaffected by the GA treatment in the apex at any time point evaluated (Additional file 12: Figure S2).

\section{Identification of transcription factors and cis-elements} potentially participating in GA-responsive gene expression We anticipate that specific, yet-unidentified transcription factors participate in promoting or repressing gene expression in response to GA, and that one or more of these may directly regulate flowering genes. We identified a total of 136 transcription factor-like genes as GAresponsive at at least one time point. These genes represented 32 diverse and well-studied transcriptional regulator classes, including AP2, bHLH, bZIP, GRAS, HD-ZIP, MADS, MYB, WRKY, and YABBY (Additional file 13: Table S10). Using a GO bioprocess enrichment analysis for GA-responsive genes in Arabidopsis that encode transcription factors, we identified $16 \mathrm{GO}$ categories showing significant enrichment in our data set. Among these, there were four categories that showed exceptional enrichment ( $\geq 5$-fold enrichment; $p$ value $<1 \mathrm{E}-04$ ): 'response to gibberellin', 'cell differentiation', 'ethylene-activated signaling pathway', and 'response to abscisic acid' (Additional file 14: Figure S3).

There were nine transcription factor-encoding genes in the category 'response to gibberellin', including the two 
GAI/RGL2-like genes discussed above. Two TCP14 (TEOSINTE BRANCHED1/ CYCLOIDEA/PROLIFERATING CELL FACTOR 14)-like genes were significantly upregulated by GA at 2 DAT (Additional file 7: Table S5). TCP14 is a direct target of DELLA proteins, and participates in GA-mediated seed germination [60]. Two homologs of Arabidopsis KNAT1 (KNOTTED-LIKE FROM Arabidopsis thaliana) were also significantly upregulated by GA (Additional file 7: Table S5). KNAT1 encodes a class I KNOX transcription factor, which regulates GA metabolic genes in the shoot apical meristem and promotes meristem function [61].

GA-responsive gene expression is expected to be mediated at least partly through the binding of transcription factors to gene regulatory cis-elements. We analyzed the promoter regions of the full set of GA-responsive genes for oligonucleotide motifs that were significantly enriched relative to the corresponding promoter regions of all expressed genes. We used a complementary approach to search for ungapped motifs of significantly overrepresented sequence patterns (see Methods). Motifs identified through these methods were compared with known cis-elements identified experimentally in previous studies by deletion analysis or by direct protein-nucleic acid binding [62, 63]. This approach resulted in the identification of potential binding sites for MYB1 (MYELOBLASTOSIS 1), WRKY14 (WRKY TRANSCRIPTION FACTOR 14), CDF5/CDF3 (CYCLING DOF FACTOR 5 or 3), bZIP48/bZIP44 (BASIC LEUCINE ZIPPER 48 or 44), and REM1 (REPRODUCTIVE MERISTEM 1) at 2 DAT (Additional file 15: Figure S4). One motif enriched at 5 DAT is the potential binding site for the homeobox transcription factor LMI1 (LATE MERISTEM IDENTITY 1) (Additional file 15: Figure S4), whose Arabidopsis homolog is characterized as a floral meristem identity gene and can interact with LFY. One enriched at 15 DAT is the potential binding site for the MYB-like transcription factor RVE (REVEILLE 1) (Additional file 15: Figure S4), whose Arabidopsis homolog is involved in hypocotyl growth by promoting auxin production [64].

To gain further insight into transcriptional networks mediating GA repression of flowering, we compared the set of GA-responsive transcription factors with the list of potential transcriptional cis-elements identified as enriched within all GA-responsive genes. We identified a single overlap: a $b Z I P 44$ homolog was identified both as a GA-responsive gene, and as a potential cognate factor for a cis-element found within GA responsive genes. In Arabidopsis, bZIP44 has been studied as a transcriptional activator of a GA-responsive mannanase gene during seed germination [65]. Both the GA-associated difference in expression and the ciselement enrichment were significant at the same time point, 2DAT, suggesting that the association is functionally relevant.

\section{Discussion}

The molecular mechanisms associated with the repression of flowering in apple and other woody perennial plants by bioactive GAs have not been extensively studied. Within the past decade, the availability of genomic data for apple has allowed for a molecular approach to studying developmental processes in this important horticultural crop, and several previous efforts have examined the involvement of a limited set of wellknown candidate genes in flowering. Here, we carried out an unbiased, high-resolution transcriptional profiling of apple shoot apices subject to the flowering-repressive effects of GA, leveraging a reproducible field model and recently released, high-quality genome sequence.

Unlike its seemingly polar effects on floral induction across plant species, GA is well known to universally promote shoot elongation. A trivial explanation for its repressive effects on flowering in apple is that, by promoting elongation of the bourse shoot, GA decreases the numbers of condensed spur structures, on which flowers are initiated $[31,40]$. In this study, however, we found no significant effect of GA on shoot architecture. This strongly argues that the effect is more direct.

At the molecular level, GA impacts gene expression within two very different arenas. Within the first, the expression of genes involved in the biosynthesis and catabolism of GAs are quickly adjusted to moderate GA concentration. These so-called feedback and feedforward mechanisms of regulation are important to maintain responsiveness to the hormone, thereby allowing the plant to use the GA signaling pathway to continuously adjust its growth and development in response to endogenous and environmental cues. Within the second, GA influences the expression of genes that direct growth and developmental processes. This study provides insight into both arenas of action within the apple shoot apex. The rapid and robust upregulation of four GA2OX genes in the apple shoot apex is consistent with findings of Fan et al. [31] in a different apple cultivar and implies participation of these genes in feedforward regulation. In rice and Arabidopsis, bioactive GA can also be catabolized through a pathway involving the EUI/ELA class of cytochrome P450 monooxygenase [5-7], and our observation that an apple ELA1-like gene is also GA responsive suggests that this protein may participate in feedforward regulation as well.

GA repressed expression of various GA signaling components, including GA transporters, receptors and DELLA repressors. NPF3.1 was identified as a GA importer in Arabidopsis roots [12], and appears to be well conserved among various plant lineages [66]. NPF3.1 shows a high affinity to $\mathrm{GA}_{4}$ compared to $\mathrm{GA}_{3}$ and $\mathrm{GA}_{1}$, and its expression is under the feedback regulation of GA such that GA application represses the expression of NPF3.1, and thus 
inhibits GA uptake [12], which is consistent with our finding in this study. The finding that GA application was also associated with decreased expression of three GID1-like receptor genes is in agreement with a previous study that concluded that GA homeostasis may be achieved not only via the regulation of GA metabolic genes, but also by the modulation of GA receptor GID1 [21]. The upregulation of the GAI- and RGL2 DELLA-genes by GA observed in this study might also reflect feedback regulation. These results collectively suggest that GA can alter the expression of both metabolic genes and signaling components to achieve GA homeostasis in the apple shoot apex.

GA-responsive genes encoding transcription factors are potential candidates for mediating of the GA-mediated flowering pathway. Our finding that transcription factorencoding, GA-responsive genes were overrepresented for functions in 'cell differentiation' and 'response to GA' is consistent with previous findings linking GAs with development, and further support that our data reflects a direct biological response to GA. Our finding that GA results in upregulation of two KNAT1 homologs is particularly interesting. Class I KNOX transcription factors, including KNAT1 and STM (SHOOT MERISTEMLESS), may participate in GA signal transduction via regulation of a wide spectrum of downstream targets, including MADS-box genes, GA20OX and GA2OX [67]. More importantly, Arabidopsis KNAT1 mediates the balance of GA and CK in the shoot apical meristem via regulating their biosynthetic and catabolic genes $[61,68-70]$. It was previously reported that a relatively low ratio of GA/CK in the apple shoot apex favors the formation of floral buds, whereas high GA/CK ratio favors vegetative buds [71], and it has been hypothesized that GA represses flowering in apple through antagonizing an inductive influence of CK [40]. Our observation that GA repressed expression of AHP1-like genes, which participate in transducing the CK signal, offers a potential mechanism for this.

We considered the possibility that, in apple, GA might directly repress expression of conserved floral promotive genes. In Arabidopsis, $S O C 1$ and $L F Y$ promote flowering as downstream targets of DELLA and GAMYB proteins, respectively [22-24]. We found no significant effects of GA on expression of homologous apple SOC1 and $L F Y$ genes, consistent with previous findings of Fan et al. [31], although neither gene was strongly expressed in non-treated plants at this time in the season (not shown). Arabidopsis $F T$ is expressed in the vasculature of leaves, and promotes flowering as protein trafficked to the shoot apex. In apple, MdFT1 transcripts are expressed to appreciable levels directly in the apex, and we anticipated that GA might downregulate this expression. However, we found no significant effect of GA on MdFT1 expression in the apex. Potentially, GA represses expression of MdFT1 and/or MdFT2 outside of the apex, with subsequent loss of $F T$ trafficking.
A previous study reported that one of two apple TFL1-like genes, MdTFL1-2, was upregulated in the shoot apex of trees treated with $\mathrm{GA}_{3}$ [49], but this was apparent only well after GA treatment (30 DAT) and late in the season (64 DAFB) when flowers would be expected to be forming. During flowering in Arabidopsis, sustained expression of TFL1 in the center of the inflorescence apex antagonizes expression of $L F Y$, allowing for the generation of floral meristems in an indeterminate manner [52]. In apple, which produces a cyme-like, determinate inflorescence, production of the characteristic, terminal 'King bloom' may be associated with suppression of a TFL1-like activity in the inflorescence apex. If MdTFL1-1 or MdTFL1-2 have a role in meristem identity in apple similar to that of TFL1 in Arabidopsis, then their relatively diminished expression in control, relative to GA-treated, plants late in the season might be an indirect consequence of flower formation. Nevertheless, the fact that transgenic suppression of MdTFL1 in apple leads to early flowering strongly argues for an independent, direct role in flowering [51]. Possibly, the MdTFL1 genes have both meristem identity and flowering functions. Our study revealed that both MdTFL1-1 and MdTFL1-2 could be induced rapidly (within 1 DAT) by $\mathrm{GA}_{4+7}$, prior to flower formation, suggesting the regulation of TFL 1 genes by GA may be relatively direct. TFL1 homologs have been well characterized in several perennial trees [72], but this is the first evidence that TFL1 may modulate flowering as a downstream effector of GA.

\section{Conclusions}

This transcriptional analysis of the response of the shoot apex to bioactive GA is a first step to identify molecular mechanisms directly connecting GA with flowering genes. Our study shows that the $\mathrm{GA}_{4+7}$ repressed flower formation without affecting shoot structure. Its application also induced the expression of a class of GA catabolic genes, GA2ox, via GA feedforward regulation, and repressed expression of GA receptors and GA transporters. Although previous experiments in other plants have shown similar regulation of GA signaling components by GA, this report reveals coordinated regulation of these multiple components. The identification of CK and other hormonal signaling components as GA responsive suggest that GA signaling interacts extensively with other hormonal signaling pathways. Our data supports several transcription factor candidates which may serve as regulators in GA-mediated repression of flowering in apple. Our study also strongly support the idea that GAs promote expression of repressive TFL1-like genes. 


\section{Methods}

\section{Plant material and growth conditions}

Trees used in 2011 and 2018 experiments were located at the MSU Research Center in Clarksville, MI and were managed in accordance with standard commercial practices for disease, insect and weed control. The date of full bloom was defined as the date on which the maximum numbers of flowers were at anthesis.

Experiments using 'Fulford Gala' were carried out in 2011, and used trees established for 20 years as grafts onto 'Mark' rootstock. Six physiologically similar trees that showed $80-90 \%$ bloom density were chosen, and all flowers were removed by hand. For each tree, five branches, each between $4 \mathrm{~cm}$ and $6 \mathrm{~cm}$ in diameter at the base, were selected and randomly assigned for apex collection dates (four branches) or for observation of bloom density the following spring (one branch). Trees were randomly assigned as three replicate pairs, with each pair comprising one tree that was treated with GA approximately 35 days after full bloom (DAFB), and one plant that was treated on the same date with water containing surfactant only. GA was applied as a mixture of $\mathrm{GA}_{4}$ and $\mathrm{GA}_{7}$ (ProVide, Valent BioSciences) at $200 \mathrm{ppm}$ $(\mathrm{mg} / \mathrm{l})$ active ingredient in aqueous solution containing $0.05 \%$ Tween-20 as surfactant. Replicate treatments were staggered by 1-2 d. Collections were made at $1,2,5$, and $15 \mathrm{~d}$ after GA treatment (DAT), corresponding to $36,37,40,50$ DAFB. On each collection date, one or two dominant buds immediately subtending the position of the inflorescence, or the apex of actively growing shoots originating from this position, were dissected using a razor blade, immediately frozen in liquid nitrogen, and stored at $-80{ }^{\circ} \mathrm{C}$. Buds and apices were less than $4 \mathrm{~mm}$ in diameter and included developing leaves less than $3 \mathrm{~mm}$ in length. Flower formation was evaluated at full bloom in the following year.

Experiments using 'Brookfield Gala' were carried out in 2018 and used 36 six-year-old trees as grafts onto 'M9-Pajam 2' rootstocks. Uniform trees were selected and divided into three groups for treatment with $\mathrm{GA}_{3}$ or $\mathrm{GA}_{4+7}$, or to serve as a control. Each group comprised three biological replicates with each replicate including four Gala trees. Shortly after full bloom, physiologically similar spurs were identified and tagged for study. For each replicate, 15 spurs were designated for sampling for each of the four time points, that is $5,10,28$, and 50 DAT, corresponding to $35,40,58$ and 80 DAFB. Gibberellins were applied using a pressure sprayer at 30 days after full bloom (June 13 2018) until leaves were drenched. $\mathrm{GA}_{4+7}$ was applied as a mixture of $\mathrm{GA}_{4}$ and $\mathrm{GA}_{7}$ at a concentration of 200 ppm; $\mathrm{GA}_{3}$ was applied at a concentration of $300 \mathrm{ppm}$; water was applied in the control. Around $0.1 \%$ Regulaid was used as surfactant for each spray. Tagged spurs were collected in the field and brought back the lab in a hydrated cooler maintained at $\sim 15 \mathrm{C}$. The first fully expanded bourse shoot leaves (around $2 \mathrm{~mm}$ at the one third base of leaves) and the adjacent bourse shoot apices were dissected from the spurs, frozen immediately in liquid nitrogen, and subsequently stored at $-80^{\circ} \mathrm{C}$ until use.

\section{Nucleic acid preparation, sequencing, and data analyses}

RNA was isolated from frozen apex samples using the method of Gasic et al. [73], with the exception that spermine was substituted for spermidine in the extraction buffer, followed by a final 'clean-up' step using a commercial kit (RNeasy Mini; Qiagen). Library preparation and sequencing used the Illumina platform and TruSeq 101-b, paired-end protocols, starting with $1 \mu \mathrm{g}$ of total RNA from each sample. The raw sequence files were filtered with fastq-mcf [74], using the parameters $-t$ 0.10 -p 15 -1 20 -q 25, to remove adapter sequences, reads less than 20 bases long, and terminal bases with a Phred score below 25. A census of filtered sequences is shown in Additional file 1.

Analyses of RNA-seq data were conducted through a pipeline comprising several off-the-shelf programs, with modifications as follows. Sequences were mapped to the GDDH13 genome sequence [56] using HISAT 2.1 [75] and assembled into transcriptional models using StringTie (version 1.3.3) [76] with default parameters, including the $-G$ option for use of a reference annotation as outlined in [77]. A merged transcriptome representing all libraries was generated with the "merge" argument in StringTie. Sequences of all transcript models are shown in Additional file 2, and genomic coordinates are shown in Additional file 6. Transcripts that showed positional overlap with genes and/or exons previously annotated in the reference genome were identified using the Gffcompare program included in the Cufflinks suite [78]. For these, the reference gene ID was used. Transcripts showing no overlap with annotated exons were defined as novel; these included those that were intergenic, fully contained within a reference intron, or that contained a reference gene within their intron(s). Novel transcripts were analyzed for homology with known sequences using the Blastn module of the Basic Local Alignment Search Tool Suite (Version 2.4.0+) and the NCBI (National Center for Biotechnology Information) non-redundant nucleotide (nt) database (updated on June 8, 2018) [79] with an Expect (E) value cutoff of 1e-12.

Loci expression levels and differences in expression were estimated using programs within the Cufflinks suite [78] as follows. Transcript models were analyzed for read representation using Cuffquant, and FPKM values were normalized for library size using Cuffnorm. Significant differences in representation among samples were determined using Cuffdiff. Differentially expressed 
genes (DEGs) were designated as significant using an adjusted $P$-value (Benjamini-Hochberg adjustment) and a false discovery rate of 0.05 . All transcript models were analyzed for homology with Arabidopsis protein models using the Basic Local Alignment Search Tool (BLAST) [80], blastx (BLAST 2.7.1+), and The Arabidopsis Information Resource (TAIR) 10 genome open reading frame translations and annotations (TAIR10_pep_20101214 updated), with an E-value cutoff of 1e-12. For each apple locus showing a match, a single representative transcript model was reported in Additional file 9 based on the highest bitscore. An apple counterpart of a given Arabidopsis protein was defined as the transcript(s) that showed highest homology to that protein, respective to all other proteins in the TAIR dataset. GO bioprocess and KEGG pathway enrichment analysis used online DAVID tools [81] and were based on the corresponding TAIR annotation. TAIR IDs for Arabidopsis homologs that encode transcription factors were obtained from Plant TFDB [82].

\section{Cis-element enrichment analysis}

The 500-bp region upstream of the translation start site was analyzed using tools within the MEME suite [83]. To cover both short and long sequence patterns, DREME (command-line version) [84] was conducted in the discriminative mode to identify relatively short $(6-8 \mathrm{bp})$ motifs, while MEME (command-line version) [85] was used to discover relatively long (up to $20 \mathrm{bp}$ ) sequence motifs. Promoters of all genes expressed (FPKM $>0$ ) at the same time point were used as control sequences $(n>40,000)$. Identified enriched motifs were compared with known motifs cataloged in two Arabidopsis motif databases (DNA affinity purification sequencing [62]; protein-binding microarrays [63]) using TOMTOM [86].

\section{TaqMan $^{\circledast}$ primer and probe design}

$\mathrm{TaqMan}^{\circ}$ gene expression assays were conducted to confirm the expression of the most significant genes of interest, including GA2OX, NPF3.1, GID1, TFL1, FT1 and FT2. To design the primers and probes specific for the target sequences, the target sequences were used as query to blast against apple nucleotide collection database (taxid: 3750) using Blastn [80]. They were then aligned with their homologs using SnapGene 2.3.2. The primers and probes (Additional file 16) were designed based such that at least one sequence of each primerprobe set was stretched over the exon junction and was specific to their target rather than any other sequences. Adenine (A) at 3' end of the primers was avoided. Each primer was $20-30 \mathrm{bp}$ long and the GC content varied from 30 to $60 \%$ and the optimal melting temperatures from $55^{\circ} \mathrm{C}$ to $62^{\circ} \mathrm{C}$. TaqMan ${ }^{\circ} \mathrm{MGB}$ (Minor Groove Binder) probes for Custom $\mathrm{TaqMan}^{\circ}$ Gene Expression
Assay were designed 1-2 bp away from the 3 '-terminal regions of the forward primers (the upstream primer) with A, $\mathrm{T}$ (Thymine) or $\mathrm{C}$ (Cytosine) as the first nucleotide, a high C/G (Guanine) ratio and a length of 15-18 bp. The length of amplicons for Custom TaqMan ${ }^{\circ}$ Gene Expression Assay was less than $150 \mathrm{bp}$. The specificity of the primers was confirmed by Primer-BLAST [87] using the template sequences and our own primers as query. The self-complementarity and 3' self-complementarity of these primers varied from 0 to 6 . The absolute $\Delta \mathrm{G}\left(\mathrm{kcal}_{\mathrm{mol}}{ }^{-1}\right)$ value for hairpin was limited under 2 . The absolute $\Delta G$ value for self-dimer and hetero-dimer was less than 9 . Primers and probe for the apple internal control gene $A C T I N$ were designed following similar rules, except for that ACTIN probe was labeled with VIC dye. ACTIN primers and probe were added into every reaction system with those of genes of interest to ensure accuracy.

\section{Taqman qRT-PCR}

Two-step Quantitative Real-Time Polymerase Chain Reaction (qRT-PCR) was conducted to confirm the expression of interesting genes using and qPCR machine (Agilent Technologies Stratagene Mx3005P). Specifically, TaqMan $^{\text {tix }}$ Gene Expression Master Mix $(10 \mu \mathrm{l}), 5 x$ diluted cDNA template $(2 \mu \mathrm{l}), A C T I N$ forward $(1 \mu \mathrm{l})$ and reverse $(1 \mu \mathrm{l})$ primers, ACTIN probe $(1 \mu \mathrm{l})$, primer-probe assay of genes of interest $(1 \mu \mathrm{l})$, and $\mathrm{ddH} 2 \mathrm{O}(4 \mu \mathrm{l})$ were added into microtubes and mixed well gently. The thermal profile used for Taqman qPCR reactions was set according to the guide (Introduction to Quantitative PCR) provided by Agilent Technologies: product was melt at $95^{\circ} \mathrm{C}$ for $15 \mathrm{~s}$, followed by 40 cycles of primer annealing and Taq DNA polymerase extension at $60^{\circ} \mathrm{C}$ for $60 \mathrm{~s}$. ROX was set as the passive reference dye.

\section{Supplementary information}

Supplementary information accompanies this paper at https://doi.org/10. 1186/s12864-019-6090-6.

Additional file 1: Table S1. Quantity and mapping rates for RNA-seq data generated for each sample.

Additional file 2. Sequence of apple shoot apex transcript models, based on alignment of sequence reads to the GDDH13 reference genome and assembly of aligned reads.

Additional file 3. Estimated expression of individual transcript models identified in this study in the GDDH13 reference genome. Expression is presented as FPKM (Fragments Per Kilobase of transcript per Million Mapped reads).

Additional file 4. Estimated expression of loci identified in this study. Additional file 5: Table S2. Classification of transcript models using GffCompare. Class codes were assigned to each transcript based on the relationship between this transcript and its closest reference transcript. Table S3. Best hits for unannotated transcripts (class codes: i, y, p, u) from BlastN and the NCBI non-redundant nucleotide collection database (nt). Table S4. Sequence length and expression of unannotated transcripts that have no hit from the nt database. 
Additional file 6. A revised feature coordinate map (GFF3) including previously annotated transcripts and transcripts identified in this study.

Additional file 7: Table S5. Differentially expressed genes in the apple bourse shoot apices in response to GA. This file contains the differentially expressed genes (DEGs) in response to GA, their coordinates, Arabidopsis homologs, gene description, expression (FPKM), Log2(Fold Change), and significance ( $p$ value, and $q$ value, which is adjusted $p$ value).

Additional file 8. Enriched GO bioprocess terms (Table S6) and KEGG pathway terms (Table S7) for GA-responsive genes. Gene Ontology bioprocess and KEGG pathway enrichment analysis were carried out using annotated terms for the most homologous Arabidopsis protein. All Arabidopsis homologs of apple genes supporting the enrichment terms are listed. GA-related terms are highlighted in red. The $P$ values for enrichment, as well as the Bonferroni and Benjamini corrected $p$ values are shown

Additional file 9: Table S8. Results of Blastx using transcript models and the Arabidopsis TAIR10 non-redundant protein database.

Additional file 10: Table S9. DEGs in the enriched plant hormone pathways based on KEGG pathway analysis. Color scales indicate upregulation (red) or downregulation (blue) of DEGs by GA.

Additional file 11: Figure S1. MdFT1 is preferably expressed in the bourse shoot apex, compared with MdFT2. A: Read counts for MdFT1 and MdFT2. Read counts were obtained from the library C5, which is RNA-seq data of CON shoot apex samples collected at 36 DAFB in 2011. B: Expression of MdFT1 and MdFT2 in shoot apex and bourse shoot leaf. Blue columns represent expression of MdFT1; pink columns represent expression of MdFT2. RT-PCR data was relative expression obtained from shoot apex on fruiting spurs at 33 DAFB in 2017.

Additional file 12: Figure S2. GA treatment does not affect the expression of MdFT1 in the bourse shoot apex. Data was obtained from the 2018 experiments. Green line represents the expression in $\mathrm{GA}_{4+7^{-}}$ treated samples, while black dash line represents $\mathrm{CON}$. Double time scales are given on $Y$ axis: DAFB, days after full bloom; DAT, days after treatment.

Additional file 13: Table S10. DEGs that potentially encode transcription factors.

Additional file 14: Figure S3. GO bioprocess enrichment analysis for DEGs that potentially encode transcription factors. GO bioprocess terms listed are all significant enriched (Benjamini-adjusted $p$ value $<0.05$ ). Fold enrichment is the enrichment magnitude of test set compared with reference.

Additional file 15: Figure S4. Enriched motifs or potential binding sites for transcription factors. Motifs with a $p$ value less than 0.05 were considered to be significantly enriched compared to the control sequences. Listed motifs were enriched at 2 DAT, except for motifs for LMI1 (5 DAT) and RVE1 (15 DAT). Short motifs (less than $8 \mathrm{bp}$ ) that were discovered by DREME and long motifs (15-20 bp) by MEME.

Additional file 16: Table S11. Taqman primers and probes for genes of interest and internal control gene (ACTIN).

\section{Abbreviations}

ABA: Abscisic Acid; AP1: APETALA1; bZIP: BASIC LEUCINE ZIPPER transcription factor(s); CDF: CYCLING DOF FACTOR; CK: cytokinin; CPS: ENT-COPALYL DIPHOSPHATE SYNTHASE; DAT: Days after Treatment; EUI: ELONGATED UPPERMOST INTERNODE; FPKM: Fragments Per Kilobase of transcript per Million mapped reads; FT: FLOWERING LOCUS T; GA: Gibberellin; GA200X: GA20 OXIDASE; GA2OX: GA2 OXIDASE; GA3OX: GA3 OXIDASE; GAI: GIBBERELLIC ACID INSENSITIVE; GID1: GIBBERELLIN-INSENSITIVE DWARF 1 ; GO: Gene Ontology; KNAT1: KNOTTED-LIKE FROM ARABIDOPSIS THALIANA 1; KO: ENT-KAURENE OXIDASE; KS: ENT-KAURENE SYNTHASE; LFY: LEAFY; LMI1: LATE MERISTEM IDENTITY 1; MYB: MYELOBLASTOSIS family of transcription factors; NPF: NITRATE TRANSPORT 1/PEPTIDE TRANSPORTER FAMILY; RGL2: REPRESSOR OF GA-LIKE 2; RVE: REVEILLE; SOC1: SUPPRESSOR OF OVEREXPRESSION OF CO 1; STM: SHOOT MERISTEMLESS; TCP14: TEOSINTE BRANCHED1/ CYCLOIDEA/PROLIFERATING CELL FACTOR 14; TFL1: TERMINAL FLOWER1; TOE1: TARGET OF EARLY ACTIVATION TAGGED 1

\section{Acknowledgements}

We thank Drs. Patrick Edger and Courtney Hollender in Department of Horticulture, Dr. Jianping Hu in Department of Plant Biology, and the Horticulture Molecular Genetics group at Michigan State University for their suggestions and support.

\section{Authors' contributions}

SVN designed the study; SZ conducted research work, analyzed the data, and generated all the figures and tables; CG conducted research work and computational analyses; SZ and SVN wrote the manuscript. All authors read and approved the final manuscript.

\section{Funding}

This work was supported by the Michigan Apple Committee.

\section{Availability of data and materials}

All data generated or analyzed during this study are included in this published article and its supplementary information files. The datasets generated and/or analysed during the current study are available in the NCBI Sequence Read Archive (SRA) (accession number: PRJNA299491), https://www.ncbi.nlm.nih.gov/bioproject?LinkName=sra_bioproject\&from_ uid $=2005070$.

Ethics approval and consent to participate

Not applicable.

\section{Consent for publication}

Not applicable.

\section{Competing interests}

The authors declare that they have no competing interests.

Received: 31 December 2018 Accepted: 9 September 2019

Published online: 16 October 2019

\section{References}

1. Davies PJ. Plant hormones: biosynthesis, signal transduction, action! Springer Netherlands; 2010.

2. Métraux JP. Gibberellins and plant cell elongation. In: Plant hormones and their role in plant growth and development. Dordrecht: Springer; 1987. p. 296-317.

3. Hedden P, Thomas SG. Gibberellin biosynthesis and its regulation. Biochem J. 2012:444:11-25.

4. Rieu I, Eriksson S, Powers SJ, Gong F, Griffiths J, Woolley L, et al. Genetic analysis reveals that C19-GA 2-oxidation is a major gibberellin inactivation pathway in Arabidopsis. Plant Cell. 2008;20(9):2420-36.

5. Zhu $Y$, Nomura $T$, Xu Y, Zhang Y, Peng Y, Mao B, et al. ELONGATED UPPERMOST INTERNODE encodes a cytochrome P450 monooxygenase that epoxidizes gibberellins in a novel deactivation reaction in rice. Plant Cell. 2006;18:442-56

6. Zhang Y, Zhang B, Yan D, Dong W, Yang W, Li Q, et al. Two Arabidopsis cytochrome P450 monooxygenases, CYP714A1 and CYP714A2, function redundantly in plant development through gibberellin deactivation. Plant J. 2011:67:342-53.

7. Nomura T, Magome H, Hanada A, Takeda-Kamiya N, Mander LN, Kamiya Y, et al. Functional analysis of arabidopsis CYP714A1 and CYP714A2 reveals that they are distinct gibberellin modification enzymes. Plant Cell Physiol. 2013;54:1837-51.

8. Park J, Lee Y, Martinoia E, Geisler M. Plant hormone transporters: what we know and what we would like to know. BMC Biol. 2017;15:1-15.

9. Chiba Y, Shimizu T, Miyakawa S, Kanno Y, Koshiba T, Kamiya Y, et al. Identification of Arabidopsis thaliana NRT1/PTR FAMILY (NPF) proteins capable of transporting plant hormones. J Plant Res. 2015;128:679-86.

10. Saito H, Oikawa T, Hamamoto S, Ishimaru Y, Kanamori-Sato M, SasakiSekimoto $Y$, et al. The jasmonate-responsive GTR1 transporter is required for gibberellin-mediated stamen development in Arabidopsis. Nat Commun. 2015;6:1-11.

11. David LC, Berquin P, Kanno Y, Seo M, Daniel-Vedele F, Ferrario-Méry S. N availability modulates the role of NPF3.1, a gibberellin transporter, in GAmediated phenotypes in Arabidopsis. Planta. 2016;244:1315-28. 
12. Tal I, Zhang Y, Jørgensen ME, Pisanty O, Barbosa ICR, Zourelidou M, et al. The Arabidopsis NPF3 protein is a GA transporter. Nat Commun. 2016;7:11486.

13. Hirano K, Ueguchi-Tanaka M, Matsuoka M. GID1-mediated gibberellin signaling in plants. Trends Plant Sci. 2008;13:192-9.

14. Ueguchi-Tanaka M, Nakajima M, Motoyuki A, Matsuoka M. Gibberellin receptor and its role in gibberellin signaling in plants. Annu Rev Plant Biol. 2007;58:183-98.

15. Davière $\mathrm{JM}$, Achard P. Gibberellin signaling in plants. Development. 2013;140(6):1147-51.

16. Thomas SG, Phillips AL, Hedden P. Molecular cloning and functional expression of gibberellin 2-oxidases, multifunctional enzymes involved in gibberellin deactivation. Proc Natl Acad Sci. 1999;96:4698-703.

17. Hedden P, Phillips AL. Gibberellin metabolism: new insights revealed by the genes. Trends Plant Sci. 2000;5:523-30.

18. Yamaguchi S, Kamiya Y. Gibberellin biosynthesis: its regulation by endogenous and environmental signals. Plant Cell Physiol. 2000;41:251-7.

19. Sun T. Gibberellin metabolism, perception and signaling pathways in Arabidopsis. Arab B. 2008;6:e0103.

20. Hytönen T, Elomaa P, Moritz T, Junttila O. Gibberellin mediates daylengthcontrolled differentiation of vegetative meristems in strawberry (Fragaria $x$ ananassa Duch). BMC Plant Biol. 2009;9:1-12.

21. Griffiths J, Murase K, Rieu I, Zentella R, Zhang ZL, Powers SJ, et al. Genetic characterization and functional analysis of the GID1 gibberellin receptors in Arabidopsis. Plant Cell. 2006;18:3399-414.

22. Blazquez MA. Gibberellins promote flowering of Arabidopsis by activating the LEAFY promoter. Plant Cell. 1998;10:791-800.

23. Moon J, Suh SS, Lee H, Choi KR, Hong CB, Paek NC, et al. The SOC1 MADSbox gene integrates vernalization and gibberellin signals for flowering in Arabidopsis. Plant J. 2003;35:613-23.

24. Achard P, Herr A, Baulcombe DC, Harberd NP. Modulation of floral development by a gibberellin-regulated microRNA. Development. 2004:131:3357-65.

25. Gocal GF, Sheldon CC, Gubler F, Moritz T, Bagnall DJ, MacMillan CP, et al. GAMYB-like genes, flowering, and gibberellin signaling in Arabidopsis. Plant Physiol. 2001;127:1682-93.

26. Yu S, Galvão VC, Zhang YC, Horrer D, Zhang TQ, Hao YH, et al. Gibberellin regulates the Arabidopsis floral transition through miR156targeted SQUAMOSA PROMOTER BINDING-LIKE transcription factors. Plant Cell. 2012;24(8):3320-32.

27. Hisamatsu T, King RW. The nature of floral signals in Arabidopsis. II. Roles for FLOWERING LOCUS T (FT) and gibberellin. J Exp Bot. 2008;59(14):3821-9.

28. Corbesier L, Vincent C, Jang S, Fornara F, Fan Q, Searle I, et al. FT protein movement contributes to long-distance signaling in floral induction of Arabidopsis. Science. 2007;316:1030-3.

29. Tamaki S, Matsuo S, Hann LW, Yokoi S, Shimamoto K. Hd3a protein is a mobile flowering signal in rice. Science. 2007;316:1033-6.

30. Lee J, Lee I. Regulation and function of SOC1, a flowering pathway integrator. J Exp Bot. 2010;61:2247-54.

31. Fan S, Zhang D, Gao C, Wan S, Lei C, Wang J, et al. Mediation of flower induction by gibberellin and its inhibitor paclobutrazol: mRNA and miRNA integration comprises complex regulatory cross-talk in apple. Plant Cell Physiol. 2018;0:1-20.

32. Bertelsen MG, Tustin DS. Suppression of flower bud formation in light cropping trees of "Pacific rose" apple using gibberellin sprays. J Hortic Sci Biotechnol. 2002;77:753-7.

33. Southwick SM, Weis KG, Yeager JT, Zhou H. Controlling cropping in Loadel cling peach using gibberellin: effects on flower density, fruit distribution, fruit firmness, fruit thinning, and yield. J Am Soc Hortic Sci. 1995;120:1087-95.

34. Goldberg-Moeller R, Shalom L, Shlizerman L, Samuels S, Zur N, Ophir R, et al. Effects of gibberellin treatment during flowering induction period on global gene expression and the transcription of flowering-control genes in citrus buds. Plant Sci. 2013;198:46-57.

35. Boss PK, Thomas MR. Association of dwarfism and floral induction with a grape 'green revolution' mutation. Nature. 2002:416:847-50.

36. Guttridge CG. Inhibition of fruit-bud formation in apple with gibberellic acid. Nature. 1962;196(4858):1008

37. Marcelle R, Sironval C. Effect of gibberellic acid on flowering of apple trees. Nature. 1963;197(4865):405

38. Luckwill LC, Silva JM. The effects of daminozide and gibberellic acid on flower initiation, growth and fruiting of apple cv. Golden delicious. J Hortic Sci. 1979:54:217-23.
39. Schmidt T, Elfving DC, McFerson JR, Whiting MD. Crop load overwhelms effects of gibberellic acid and ethephon on floral initiation in apple. HortScience. 2009;44:1900-6.

40. Zhang S, Zhang D, Fan S, Du L, Shen Y, Xing L, et al. Effect of exogenous GA3 and its inhibitor paclobutrazol on fl oral formation, endogenous hormones, and flowering-associated genes in ' Fuji ' apple (Malus domestica Borkh .). Plant Physiol Biochem. 2016;107:178-86.

41. Goldschmidt EE, Eilati SK. Gibberellin-treated Shamouti oranges: effects on coloration and translocation within peel of fruits attached to or detached from the tree. Bot Gaz. 1970;131:116-22.

42. Greene DW. Reducing floral initiation and return bloom in pome fruit trees - applications and implications. Horttechnology. 2000;10:740-3.

43. González-Rossia D, Juan M, Reig C, Agustí M. The inhibition of flowering by means of gibberellic acid application reduces the cost of hand thinning in Japanese plums (Prunus salicina Lindl.). Sci Hortic (Amsterdam). 2006;110:319-23.

44. Southwick SM, Fritts R. Commercial chemical thinning of stone fruit in California by gibberellins to reduce flowering. Plant Bioregulators Hortic. 1994;394:135-48

45. Lenahan OM, Whiting MD, Elfving DC. Gibberellic acid inhibits floral bud induction and improves "Bing" sweet cherry fruit quality. HortScience. 2006;41:654-9.

46. Costa G, Vizzotto G. Fruit thinning of peach trees. Plant Growth Regul. 2000;31:113-9.

47. McArtney SJ, Tustin DS, Seymour S, Cashmore W, Looney NE. Benzyladenine and carbaryl effects on fruit thinning and the enhancement of return flowering of three apple cultivars. J Hortic Sci. 1995;70:287-96.

48. Li Y, Zhang D, Xing L, Zhang S, Zhao C, Han M. Effect of exogenous 6benzylaminopurine (6-BA) on branch type, floral induction and initiation, and related gene expression in 'Fuji' apple (Malus domestica Borkh). Plant Growth Regul. 2016;79:65-70.

49. Haberman A, Ackerman M, Crane O, Kelner JJ, Costes E, Samach A. Different flowering response to various fruit loads in apple cultivars correlates with degree of transcript reaccumulation of a TFL1-encoding gene. Plant J. 2016;87:161-73.

50. Kotoda N, Wada M. MdTFL1, a TFL1-like gene of apple, retards the transition from the vegetative to reproductive phase in transgenic Arabidopsis. Plant Sci. 2005;168:95-104.

51. Kotoda N, Iwanami H, Takahashi S, Abe K. Antisense expression of MdTFL1, a TFL1-like gene, reduces the juvenile phase in apple. J Am Soc Hortic Sci. 2006;131:74-81.

52. Liljegren SJ. Interactions among APETALA1, LEAFY, and TERMINAL FLOWER1 specify meristem fate. Plant Cell. 1999;11:1007-18.

53. Buban T, Faust M. Flower bud induction in apple trees: internal control and differentiation. Hortic Rev. 1982:4:174-203.

54. Foster T, Johnston R, Seleznyova A. A morphological and quantitative characterization of early floral development in apple (malus $x$ domestica Borkh.). Ann Bot. 2003;92:199-206.

55. Luckwill LC, Weaver P, MacMillan J. Gibberellins and other growth hormones in apple seeds. J Hortic Sci. 1969;44:413-24.

56. Daccord N, Celton JM, Linsmith G, Becker C, Choisne N, Schijlen E, et al. High-quality de novo assembly of the apple genome and methylome dynamics of early fruit development. Nat Genet. 2017;49:1099-106 https:/ iris.angers.inra.fr/gddh13/. Accessed 17 Aug 2017.

57. Sung S-K, Yu G-H, An G. Characterization of MdMADS2, a member of the SQUAMOSA subfamily of genes, in apple. Plant Physiol. 1999;120:969-78.

58. Kotoda N, Wada M, Kusaba S, Kano-Murakami Y, Masuda T, Soejima J. Overexpression of MdMADS5, an APETALA1-like gene of apple, causes early flowering in transgenic Arabidopsis. Plant Sci. 2002;162(5):679-87.

59. Kotoda N, Hayashi H, Suzuki M, Igarashi M, Hatsuyama Y, Kidou Sl, et al. Molecular characterization of flowering LOCUS t-like genes of apple (malus $\times$ domestica borkh.). Plant Cell Physiol. 2010;51 (4):561-75.

60. Resentini F, Felipo-Benavent A, Colombo L, Blázquez MA, Alabadí D, Masiero S. TCP14 and TCP15 mediate the promotion of seed germination by gibberellins in arabidopsis thaliana. Mol Plant. 2015;8:482-5.

61. Jasinski S, Piazza P, Craft J, Hay A, Woolley L, Rieu I, et al. KNOX action in Arabidopsis is mediated by coordinate regulation of cytokinin and gibberellin activities. Curr Biol. 2005;15:1560-5.

62. O'Malley RC, Huang S, shan C, Song L, Lewsey MG, Bartlett A, et al. Erratum: Cistrome and epicistrome features shape the regulatory DNA landscape. Cell. 2016;166:1598. 
63. Franco-Zorrilla JM, López-Vidriero I, Carrasco JL, Godoy M, Vera P, Solano R. DNA-binding specificities of plant transcription factors and their potential to define target genes. Proc Natl Acad Sci. 2014;111:2367-72.

64. Rawat R, Schwartz J, Jones MA, Sairanen I, Cheng Y, Andersson CR, et al. REVEILLE1, a Myb-like transcription factor, integrates the circadian clock and auxin pathways. Proc Natl Acad Sci. 2009:106:16883-8.

65. Iglesias-Fernández R, Barrero-Sicilia C, Carrillo-Barral N, Oñate-Sánchez L, Carbonero P. Arabidopsis thaliana bZIP44: a transcription factor affecting seed germination and expression of the mannanase-encoding gene AtMAN7. Plant J. 2013:74:767-80.

66. Léran S, Varala K, Boyer JC, Chiurazzi M, Crawford N, Daniel-Vedele F, et al. A unified nomenclature of nitrate transporter 1/peptide transporter family members in plants. Trends Plant Sci. 2014;19:5-9.

67. Tsuda K, Hake S. Diverse functions of KNOX transcription factors in the diploid body plan of plants. Curr Opin Plant BiolElsevier Ltd. 2015;27:91-6.

68. Sakamoto T, Kobayashi M, Itoh H, Tagiri A, Kayano T, Tanaka H, et al. Expression of a gibberellin 2-oxidase gene around the shoot apex is related to phase transition in rice. Plant Physiol. 2001;125:1508-16.

69. Yanai O, Shani E, Dolezal K, Tarkowski P, Sablowski R, Sandberg G, et al. Arabidopsis KNOXI proteins activate cytokinin biosynthesis. Curr Biol. 2005;15:1566-71.

70. Bolduc N, Hake S. The maize transcription factor KNOTTED1 directly regulates the gibberellin catabolism gene GA2ox1. Plant Cell. 2009;21:1647-58

71. Luckwill LC. The control of growth and fruitfulness of apple trees. Physiol tree Crop. 1970:237-54.

72. Hanke MV, Flachowsky H, Peil A, Hättasch C. No flower no fruit genetic potentials to trigger flowering in fruit trees. Genes, Genomes Genomics. 2007;1:1-20.

73. Gasic K, Hernandez A, Korban SS. RNA extraction from different apple tissues rich in polyphenols and polysaccharides for cDNA library construction. Plant Mol Biol Rep. 2004;22:437-8.

74. Aronesty E. Ea-utils : command-line tools for processing biological sequencing data. Expr Anal Durham. 2011;2 https://expressionanalysis. github.io/ea-utils/ Accessed on 1 May 2017.

75. Kim D, Langmead B, Salzberg SL. HISAT: a fast spliced aligner with low memory requirements. Nat Methods. 2015;12:357-60 https://ccb.jhu.edu/ software/hisat2/index.shtml. Accessed on 5 Sep 2017.

76. Pertea M, Pertea GM, Antonescu CM, Tsung-Cheng C, Mendell JT, Salzberg SL. StringTie enables improved reconstruction of a transcriptome from RNAseq reads. Nat Biotechnol. 2015;33:290-5.

77. Pertea M, Kim D, Pertea GM, Leek JT, Salzberg SL. Transcript-level expression analysis of RNA- seq experiments with HISAT, StringTie and transcript-level expression analysis of RNA-seq experiments with HISAT, StringTie and Ballgown. Nat Protoc. 2016;11:1650-67 http://ccb.jhu.edu/software/stringtie/. Accessed on 13 Sep 2017.

78. Trapnell C, Roberts A, Goff L, Pertea G, Kim D, Kelley DR, et al. Differential gene and transcript expression analysis of RNA-seq experiments with TopHat and cufflinks. Nat Protoc. 2012;7:562-78 http://cole-trapnell-lab. github.io/cufflinks/. Accessed on 18 Sep 2017.

79. BLAST databases. ftp://ftp.ncbi.nlm.nih.gov/blast/db/. Accessed 11 June 2018.

80. Altschul SF, Gish W, Miller W, Myers EW, Lipman DJ. Basic local alignment search tool. J Mol Biol. 1990;215:403-10 https://blast.ncbi.nlm.nih.gov/Blast. cgi. Accessed on 25 May 2018.

81. Huang DW, Sherman BT, Lempicki RA. Systematic and integrative analysis of large gene lists using DAVID bioinformatics resources. Nat Protoc. 2009;4: 44-57 https://david.ncifcrf.gov. Accessed on 17 Jan 2018.

82. Jin J, Tian F, Yang DC, Meng YQ, Kong L, Luo J, et al. PlantTFDB 4.0: toward a central hub for transcription factors and regulatory interactions in plants. Nucleic Acids Res. 2017;45:D1040-5 http://planttfdb.cbi.pku.edu.cn/index. php?sp=Ath. Accessed 15 Jan 2018.

83. Bailey TL, Boden M, Buske FA, Frith M, Grant CE, Clementi L, et al. MEME suite: tools for motif discovery and searching. Nucleic Acids Res. 2009;37: 202-8 http://meme-suite.org. Accessed on 4 May 2018

84. Bailey TL. DREME: motif discovery in transcription factor ChIP-seq data. Bioinformatics. 2011;27:1653-9.

85. Bailey $\mathrm{TL}$, Elkan C. Fitting a mixture model by expectation maximization to discover motifs in biopolymers. Proc Second Int Conf Intell Syst Mol Biol. 1994:28-36.

86. Gupta S, Stamatoyannopoulos JA, Bailey TL, Noble WS. Quantifying similarity between motifs. Genome Biol. 2007:8(2):R24
87. Ye J, Coulouris G, Zaretskaya I, Cutcutache I, Rozen S, Madden TL. PrimerBLAST: a tool to design target-specific primers for polymerase chain reaction. BMC Bioinformatics. 2012;13(1):134 https://www.ncbi.nlm.nih.gov/ tools/primer-blast/. Accessed on 6 Apr 2018.

\section{Publisher's Note}

Springer Nature remains neutral with regard to jurisdictional claims in published maps and institutional affiliations.
Ready to submit your research? Choose BMC and benefit from:

- fast, convenient online submission

- thorough peer review by experienced researchers in your field

- rapid publication on acceptance

- support for research data, including large and complex data types

- gold Open Access which fosters wider collaboration and increased citations

- maximum visibility for your research: over $100 \mathrm{M}$ website views per year

At BMC, research is always in progress.

Learn more biomedcentral.com/submissions 